\title{
Assessing changes in soil conservation ecosystem services and causal factors in the Three Gorges Reservoir region of China
}

\author{
Qiang Xiao ${ }^{\mathrm{a}, \mathrm{b}}$, Dan $\mathrm{Hu}^{\mathrm{a},{ }^{*}}$, Yang Xiao ${ }^{\mathrm{a}}$ \\ a State Key Laboratory of Urban and Regional Ecology, Research Center for Eco-Environmental Sciences, Chinese Academy of Sciences, Beijing 100085, China \\ ${ }^{\mathrm{b}}$ Chongqing College of Arts and Sciences, Chongqing 402160, China
}

\section{A R T I C L E I N F O}

Article history:

Received 2 July 2015

Received in revised form

15 August 2016

Accepted 2 September 2016

Available online 4 September 2016

\section{Keywords:}

Soil conservation

Ecosystem service

Chongqing City

Hubei Province

InVEST

Universal soil loss equation

\begin{abstract}
A B S T R A C T
Ecosystem services provide the basis for humankind to survive and develop. Similarly, soil conservation services play an important role in maintaining regional ecological protection and sustainable development. Concerned with both the capacity of soil conservation and the strengthening soil conservation efforts, soil conservation services greatly contribute to enhancing ecosystem management and wellbeing. It is based on a suite of ecosystem service models, the Integrated Valuation of Ecosystem services and Trade-offs, which evaluates ecosystem services and weigh gains and losses. Accordingly, this study analyzes spatial characteristics of soil conservation functions for ecosystems in China's Three Gorges Reservoir region and discusses factors that influence them. Results show that increases in the value of soil conservation services was in the northeastern part of the study area, in counties stretching from Yunyang to Zigui. These areas accounted for $83.4 \%$ of the total area where there was an increase in soil conservation services. An important predictor of soil conservation services is slope, which explained $63 \%$ of the variability in soil conservation services. The soil conservation function of ecosystems is crucial in maintaining the ecological balance in the Three Gorges Reservoir region and plays an important role in protecting the area by preventing land deterioration and river sedimentation. Findings from this study show that analysis from the standpoint of the relationship between soil conservation processes and ecological services of spatial structure is recommended. The aim of this study was to provide new understanding of the practice of soil conservation as well as offer innovation in research methods of soil conservation.
\end{abstract}

(C) 2016 Elsevier Ltd. All rights reserved.

\section{Introduction}

Ecosystem services provide the basis for humankind to survive and develop. The soil conservation service plays an important role in preventing a major global environmental problem (soil erosion) and in maintaining regional ecological safety, thereby increasing the potential for sustainable development (McDonough et al., 2014; Zhang et al., 2013; Faverial and Sierra, 2014). Costanza reports that erosion control and prevention of sedimentation in water bodies are important ecosystem service functions (Costanza et al., 1997). Erosion and sedimentation are natural processes in healthy ecosystems, but erosion and sedimentation that exceed an ecosystem's ability to cope will have serious negative consequences (Aiello et al., 2015; Zhou et al., 2015). For example, excessive soil erosion

\footnotetext{
* Corresponding author. Tel.: +86 1062849199.

E-mail address: hudan@rcees.ac.cn (D. Hu).
}

will cause ecosystem fragmentation, decreased soil fertility, declining land quality, and increases in the frequency of flooding. Furthermore, erosion can lead to sediment accumulation in reservoirs, thereby decreasing the capacity of reservoirs, leading to degradation of the aquatic environment, endangering both reservoirs and downstream areas (Chen et al., 2015).

The Universal Soil Loss Equation (USLE) is the most widely used method to estimate potential soil erosion and soil conservation because it accounts for rainfall, soil properties, topography, vegetation cover, and management factors (Cohen et al., 2005; Lee, 2004). In previous studies, USLE has been used to study soil erosion and its spatial framework, soil conservation (as an ecosystem service function), and impacts of human activities on water conservation (Ngetich et al., 2014).

One drawback of USLE is that it does not account for terrain to intercept upstream sediments (Cao et al., 2015a; Qu et al., 2014; Li et al., 2014a). The amount of soil conservation calculated according to USLE is therefore potentially inaccurate. This problem has been 
solved to some extent by the Integrated Valuation of Ecosystem Services and Trade-offs (InVEST) software suite (Borges et al., 2014; Yang et al., 2015). Compared to traditional assessment methods, InVEST offers two innovations: first, it accounts for the capacity of land to intercept upstream sediments, thereby improving the accuracy of sediment conservation calculations; second, reservoir data are added to better target assessment results to support management decisions (Al-Wadaey and Ziadat, 2014; Miao et al., 2015).

InVEST was jointly developed by Stanford University, The Nature Conservancy, and the World Wildlife Fund. Its goal is to simulate ecosystem services provided by different land covers and estimate their value, thus providing a scientific basis for assessing the benefits and ecosystem impacts of human activity (Bratman et al., 2015; Zheng and Cao, 2015). The software has been successfully applied in China's Sichuan and Beijing provinces as well as in Tanzania and Hawaii (Liu et al., 2014a; Cao and Zhang, 2015; Li et al., 2015). The software has been used to assess water conservation, water supply, water yield, biological diversity, carbon sequestration, and other ecosystem service functions, but few used InVEST to assess the soil conservation function (Kinzig et al., 2013; Mendenhall et al., 2014b; Zhang et al., 2016).

China's Three Gorges Reservoir is one of the world's largest, and now that it is at the stage where it has begun to store large amounts of water, the surrounding area has entered into a new stage of rapid socioeconomic development that will create challenging stress on the ecological environment (Guo et al., 2003; Yan et al., 2003). Soil erosion in this area will potentially eliminate some land types, cause a decline in land productivity, lead to sediment accumulation in water bodies, and increase the frequency of flooding and drought, thereby threatening both the reservoir and the lives of those who depend on it (Cao et al., 2015b; Yang et al., 2014). Thus, it is crucial to quantify the rate of soil erosion in the Three Gorges Reservoir region, to identify key areas for water and soil protection, to detect key factors responsible for soil erosion, and to plan and implement appropriate prevention or mitigation measures. However, there has been no systematic quantitative analysis of soil erosion in this region (Wang et al., 2014a; Yang et al., 2014; Tao et al., 2015).

To provide some of the necessary data, this study used the InVEST software suite to estimate annual average soil erosion in the region of the reservoir as well as its spatial distribution. The goal of this study was to provide insight into the soil conservation ecological service function and the factors that influence how ecosystems in the study area provide this function. The aim of this study is to provide scientific guidance for maintaining and managing the soil conservation function in the region surrounding the Three Gorges Reservoir.

\section{Study area and methods}

\subsection{The study area}

The region of the Three Gorges Reservoir (Fig. 1) is located between $28^{\circ} 56^{\prime} \mathrm{N}$ and $31^{\circ} 44^{\prime} \mathrm{N}$ and between $106^{\circ} 16^{\prime} \mathrm{E}$ and $111^{\circ} 28^{\prime} \mathrm{E}$, comprising the lower section of the upper reaches of the Yangtze River. The region encompasses 26 cities or counties in Chongqing City (a provincial-scale municipality) and Hubei Province, and its total area of $57,802 \mathrm{~km}^{2}$ supports a population of 20.1 million (Liu et al., 2014b). The dominant soil types are purple, yellow, and paddy soils. The region has a subtropical monsoon climate, characterized by highly variable spring weather, humid and hot summers, dry autumns, and dry and cold winters (Chai et al., 2014). The mean annual precipitation is approximately $1100 \mathrm{~mm}$. Rainfall is variable in amount and timing, but $85 \%$ of annual rainfall occurs during the summer (6-9 months per year).

The reservoir region is undergoing rapid population growth and economic development, and the ecological environment is changing rapidly due to the impacts of urban expansion, excessive cultivation, and over felling of forests. The river is also receiving increasing inputs of domestic sewage, industrial waste, and agricultural pesticides and fertilizers, leading to serious water pollution (Austin et al., 2013; Cao, 2015). Due to a combination of natural factors (such as increased precipitation) and recent human activities, soil erosion is becoming more and more serious in sections of this region. In addition, the loss of natural habitat, combined with habitat degradation and fragmentation, is seriously threatening biodiversity.

\subsection{Data sources}

The meteorological data used in this study include precipitation and temperature from 2000 to 2010 on a monthly timescale. This study applied monthly data from meteorological stations distributed throughout the study area, and interpolation of the data (with a spatial resolution of $0.05^{\circ}$ ), using the Kriging method, covers the entire area. For all spatial analysis, this study used ArcGIS software version 10.1 (www.esri.com). In addition, this study used a digital elevation model created in 2005 by the Institute of Geographic Sciences and Natural Resources, Chinese Academy of Sciences (http://english.igsnrr.cas.cn), to calibrate monthly temperature. For this calculation, this study used an environmental lapse rate of $0.47^{\circ} / 100 \mathrm{~m}$ for increases in elevation (Wu et al., 2016). This coefficient derives from a linear regression between elevation and temperature in the study region.

Soil data derives from China's second national soil survey. This information includes soil types, their particle-size distribution, soil organic matter content, and soil depth at a scale of 1:1 000000.

Topographic data derive from NASA's Shuttle Radar Topography Mission (http://www:jpl.nasa.gov/srtm) digital elevation model, with a horizontal resolution of $90 \mathrm{~m}$. This study used this information to compute slope gradients and lengths. Because the normalized difference vegetation index (NDVI) is a good indicator of vegetation cover, this study used the Moderate Resolution Imaging Spectroradiometer (MODIS) time series NDVI dataset from 2000 to 2010 . The spatial resolution was $1 \mathrm{~km}$, and the time interval was 16 days. Because cloud cover, atmospheric conditions, and ice and snow cover can affect MODIS products, this study used the asymmetric Gaussian filter during data pre-processing to reduce noise and improve data quality. This study used TIMESAT 2.3 software (http://web.nateko.lu.se/timesat/timesat.asp). To further eliminate noise, this study compiled resultant 16-day MODIS NDVI data into monthly NDVI data by applying composites of maximum values to the two NDVI images of each month.

Information on the distribution of land use and cover types in the study area derived from interpreting Landsat MSS and TM data provided by the Chinese Academy of Sciences. This study used precise diachronic classifications of these areas as references for object-oriented classification (Zhang et al., 2014; Kyalo et al., 2014) based on 30-m-resolution Landsat images from the beginning of the dry season (i.e., the time of maximum vegetation cover) from 1999 to 2001, 2004 to 2006, and 2009 to 2011. Based on groundtruth data, the overall accuracy of the land use and cover type map was $91.2,90.4$, and $89.1 \%$, respectively, for the three periods.

This study used statistical yearbooks and government data as sources of socioeconomic data. These included urban population density (UPD), the proportion of regional gross domestic product (GDP), and the proportion of the total accounted for by GDP1 (agricultural GDP), GDP2 (industrial GDP), and GDP3 (service industry GDP). 


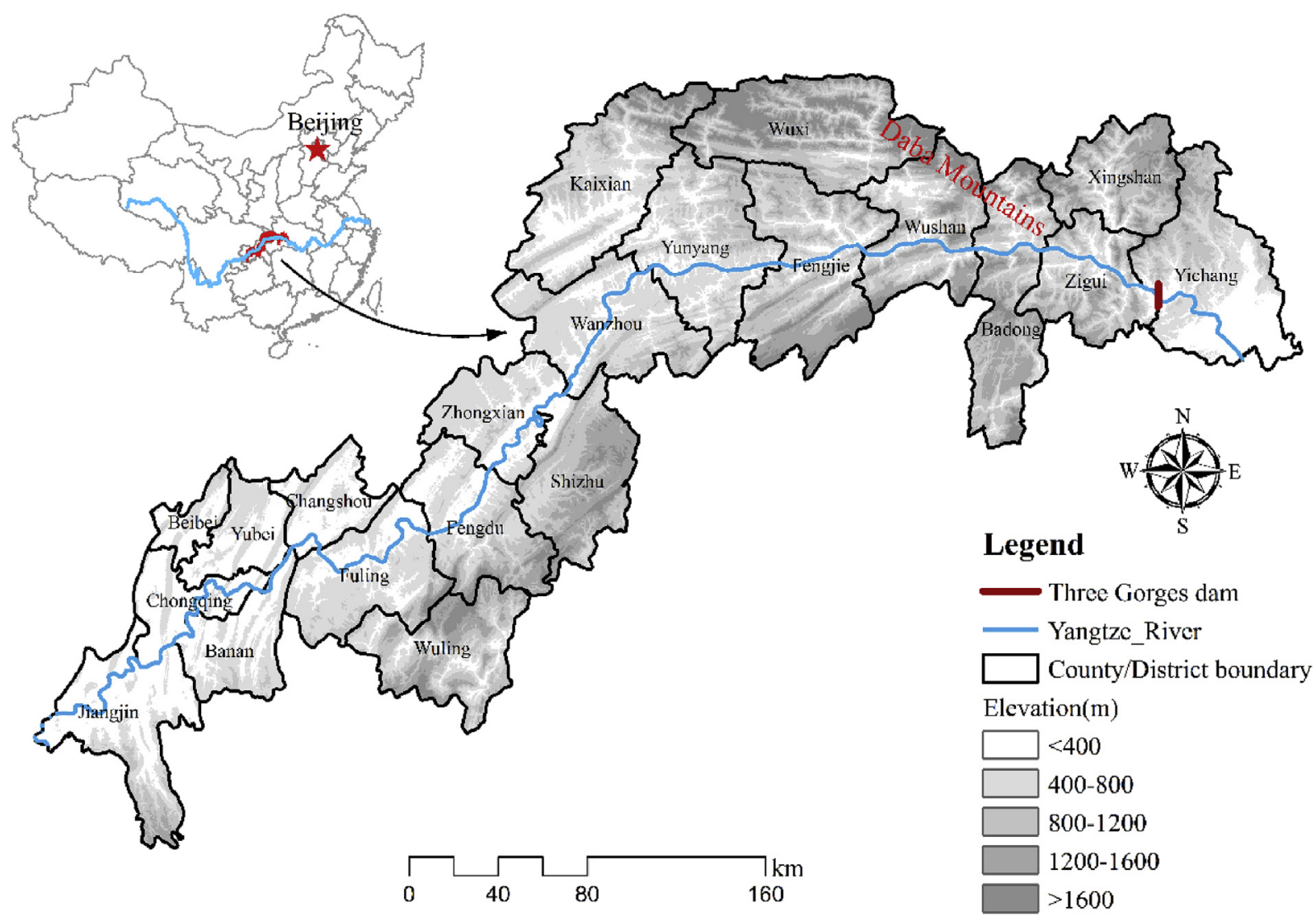

Fig. 1. Location of the Three Gorges Reservoir region.

In this study, soil erosion data originally derived from soil erosion reports and water conservancy annals of the Chongqing Municipality and Hubei Province. All data from this study can be simply grouped into cartographic data and statistics. The conversion of all cartographic raster data to the same UTM coordinate system has a spatial resolution of $90 \mathrm{~m}$. Table 1 summarizes the primary data sources this study used for analysis.

\subsection{Methods}

The USLE is an empirical model that predicts the average annual soil loss and its spatial distribution (Irvem et al., 2007). The basic form of the USLE is as follows (Thierfelder and Wall, 2012; Tao et al., 2015):

$S E=R \times K \times L S \times C \times P$ where SE represents soil erosion $\left(\mathrm{t} \mathrm{ha}^{-1} \mathrm{yr}^{-1}\right) ; R$ is the rainfall erosivity factor (MJ mm ha ${ }^{-1} \mathrm{~h}^{-1} \mathrm{yr}^{-1}$ ); $K$ is the soil erodibility factor ( $\mathrm{t}$ ha $\mathrm{h} \mathrm{ha} \mathrm{h}^{-1} \mathrm{MJ}^{-1} \mathrm{~mm}^{-1}$ ); $L S$ is a dimensionless topographic factor; $C$ is a dimensionless vegetation cover factor; and $P$ is a dimensionless conservation practice factor.

Supported by remote sensing data as inputs and geographical information system (GIS) technologies, past application of the USLE model was in estimating soil loss in river basins and other land forms around the world (Van den Putte et al., 2010). Effort to improve the accuracy of calculations of various factors in the USLE model is ongoing (Franzluebbers, 2010).

The ecosystem soil conservation service (SCS) value is describable in many ways. One common method is based on soil erosion prevention (Lou et al., 2012), which represents the difference between soil erosion without vegetation cover (i.e., potential soil erosion) and soil erosion under the current land use or land cover type patterns, including soil erosion control practices (i.e., actual

Table 1

Sources of the primary data.

\begin{tabular}{|c|c|c|}
\hline Data type & $\begin{array}{l}\text { Resolution or spatial } \\
\text { distribution }\end{array}$ & Data source \\
\hline Precipitation, temperature & 78 points & $\begin{array}{l}\text { Chinese National Meteorological Information Center, China Meteorological } \\
\text { Administration }\end{array}$ \\
\hline Soil map & $1: 1000000$ & Chinese Academy of Sciences \\
\hline $\begin{array}{l}\text { Shuttle Radar Topography Mission digital elevation } \\
\text { model }\end{array}$ & $90 \mathrm{~m}$ & International Scientific Data Service Platform \\
\hline Land cover map & $90 \mathrm{~m}$ & Chinese Academy of Sciences, \\
\hline MODIS-NDVI & $250 \mathrm{~m}$ & Land Processes Distributed Active Archive Center \\
\hline Urban population & Counties & Statistical Yearbook \\
\hline GDP data & Counties & Statistical Yearbook \\
\hline
\end{tabular}


soil erosion). SCS is expressed as follows:

$S C S=S E_{p}-S E a=R \times K \times L S \times(1-C)$

where $S E_{\mathrm{p}}$ and $S E_{\mathrm{a}}$ denote the potential and actual soil erosion rates, which are calculated as follows:

$S E_{p}=R \times K \times L S$

$S E_{a}=R \times K \times L S \times C$

\subsubsection{Rainfall erosivity factor $(R)$}

Rainfall erosivity, which reflects the potential capacity of rainfall to cause erosion, is determined by a combination of the kinetic energy and intensity of rainfall. Based on rainfall data availability, this study applied $R$ value calculations from 2000 to 2010 using monthly average rainfall and an empirical equation proposed by Renison and Shen (Renison et al., 2010; Shen et al., 2010).

$R=\sum_{i=1}^{12} 1.735 \times 10^{\left(1.5 \times \log \left(p_{i}^{2} / p\right)-0.919\right)}$

where $P_{i}$ is the total rainfall $(\mathrm{mm})$ in month $i$, and $P$ is the total annual rainfall $(\mathrm{mm})$.

\subsubsection{Soil erodibility factor $(K)$}

Soil erodibility is defined as the amount of eroded soil per unit area caused by rainfall erosivity, and it reflects differences in soil erosion rates when other factors that influence erosion are constant. The physical properties of soil, such as texture, particle-size distribution, stability of structure, clay types, permeability, organic matter content, and soil thickness affect erosion rates. This study used the formula from the Erosion/Productivity Impact Calculator (EPIC) for this calculation, based on a revision by Zhang et al. (2016), to improve its applicability to properties of Chinese soils (Zhang et al., 2016).

$$
\begin{aligned}
K_{\text {EPIC }}= & \left\{0.2+0.3 \exp \left[-0.0256 m_{s}\left(1-m_{\text {silt }} / 100\right)\right]\right\} \\
& \times\left[m_{\text {silt }} /\left(m_{c}+m_{\text {silt }}\right)\right]^{0.3} \times\{1-0.25 \operatorname{org} C /[\operatorname{org} C \\
& +\exp (3.72-2.95 \operatorname{org} C)]\} \times\left\{1-0.7\left(1-m_{s} / 100\right) /\right. \\
& \left.\left\{\left(1-m_{s} / 100\right)+\exp \left[-5.51+22.9\left(1-m_{s} / 100\right)\right]\right\}\right\}
\end{aligned}
$$

$K=\left(-0.01383+0.51575 K_{E P I C}\right) \times 0.1317$

where $K$ is the soil erodibility factor ( $\mathrm{t}$ ha $\mathrm{h} \mathrm{ha}^{-1} \mathrm{MJ}^{-1} \mathrm{~mm}^{-1}$ ); and $m_{\mathrm{s}}, m_{\text {silt }}, m_{\mathrm{c}}$, and $\operatorname{org} C$ are the mass-based percentages of sand, silt, clay, and organic carbon, respectively.

\subsubsection{Topographic factors ( $L S)$}

$L S$ accounts for the effects of slope length $(L)$ and steepness $(S)$ on soil erosion. Although the exact relationship between these factors remains uncertain, this study assumed that a greater flow accumulation and a faster runoff velocity, respectively, is associated with a longer slope length and a steeper slope. It is also assumed that the erosion rate would stop increasing when the slope reaches a certain threshold value (Luo et al., 2014). Calculation of the $L S$ factor used improved equations for the $L$ and $S$ factors based on the proposed procedure:
$L=(\lambda / 22.13)^{m}$

where

$m=\beta /(1+\beta)$ and $: \beta=(\sin \theta / 0.089) /\left[3.0 \sin \theta^{0.8}+0.56\right]$

$S=\left\{\begin{array}{cc}10.8 \sin \theta+0.03 & \theta<5.14^{\circ} \\ 16.8 \sin \theta-0.5 & 5.14^{\circ} \leq \theta<10.20^{\circ} \\ 21.91 \sin \theta-0.96 & 10.20^{\circ} \leq \theta<28.81^{\circ} \\ 9.5988 & \theta>28.81^{\circ}\end{array}\right.$

where $L$ is the slope length factor; $S$ is the slope steepness factor; $m$ is the slope length index; $\theta$ is the slope gradient $\left(^{\circ}\right)$; and $\lambda$ is the horizon slope length $(\mathrm{m})$.

\subsubsection{Vegetation cover factor (C)}

Vegetation plays a significant role in controlling soil erosion (Mwaniki et al., 2015; Vandandorj et al., 2015). Vegetation cover is therefore critical for soil and water conservation, particularly since it is highly sensitive to natural and anthropogenic activities (Dick et al., 2015). The calculation of $C$ on a regional scale relies on an empirically derived lookup table that represents the mean vegetation cover for each land use and land cover type in a study area and is defined in terms of land use. However, this method cannot account for differences in a given land use type among sites, nor can it reflect differences such as conditions of vegetation or differences among phenological phases of vegetation. This study used $C$ to determine the form of NDVI proposed by Jones. The calculation of average $C$ from 2000 to 2010 in the study area was based on coarseresolution MODIS NDVI data:

$C_{i}=\exp \left\{-\alpha\left[N D V I_{i} /\left(\beta-N D V I_{i}\right)\right]\right\}$

where $\mathrm{NDVI}_{i}$ represents the NDVI value for the cover type, $i$ represents the pixel in the study area, and $\alpha$ and $\beta$ are parameters that define the shape of the curve (Shen et al., 2016). In the study area, numerous tests of this equation indicated that one can obtain optimal results when $\alpha=2$ and $\beta=1$ (Zhu et al., 2012). Although certain questions remain concerning the calculation of $C$ from NDVI, this method is one of the simplest and most practical ways to obtain $C$ on a regional scale. Table 2 provides $C$ values of the key natural vegetation types in the study area.

\subsubsection{Erosion control practice factor $(P)$}

The $P$ factor is defined as the predicted ratio of soil loss for a given soil conservation practice to soil loss that would occur after plowing up and down a slope. $P$ value determination in this study was based on research results from Teng et al. (2016) for each of the land use and land cover types in the study area (Table 3).

Table 2

Values of the vegetation cover factor $(C)$ for the main ecosystems in the Three Gorges Reservoir region.

\begin{tabular}{lllllll}
\hline \multirow{2}{*}{ Ecosystem type } & \multicolumn{7}{l}{ Vegetation cover (\%) } \\
\cline { 2 - 7 } & $<10$ & $10-30$ & $30-50$ & $50-70$ & $70-90$ & $>90$ \\
\hline Forest & 0.10 & 0.08 & 0.06 & 0.02 & 0.004 & 0.001 \\
Shrubs & 0.40 & 0.22 & 0.14 & 0.085 & 0.040 & 0.011 \\
Grasslands & 0.45 & 0.24 & 0.15 & 0.09 & 0.043 & 0.011 \\
\hline
\end{tabular}




\subsection{Data analyses}

\subsubsection{Trend analysis and significance tests}

This study used least squares linear regression to determine trends in each pixel to detect variations in SCS and SE trends during the study period (from 2000 to 2010). This study applied SPSS software version 17.0 (http://www.ibm.com/software/analytics/ spss) to calculate Pearson's correlation coefficient values to obtain relationships between climatic variables and SCS and SE.

Finally, this study used IDL software version 5.0 (http://www. exelisvis.com) to conduct calculations.

\subsubsection{Redundancy analysis}

To quantify the effect of climate and human activities on trends in SCS and SE and reveal their relative contributions in determining spatial characteristics of SCS, this study applied a constrained ordination technique (redundancy analysis; RDA) using CANOCO software version 4.5 (Lopez-Garrido et al., 2011; Li et al., 2014b). In comparison to other methods, such as principal component analysis, correlation analysis, and regression analysis, RDA offers advantages in that it can independently maintain contributions of each variable.

\section{Results}

\subsection{Spatial distribution of SCS and changes over time}

The distribution of the SCS values was highly spatially heterogeneous, with the highest SCS values in the northeast and lowest SCS values in the southwest (Fig. 2a-c). The highest SCS (>5000 $\mathrm{tha}^{-1} \mathrm{yr}^{-1}$ ) was primarily located in the ecosystems in the Daba Mountains.

For linear regression of SCS as a function of time, results show significant trends in certain areas (Fig. 2c). For purposes of simplicity, this study defined areas with no changes in SCS as areas with magnitude of changes less than $50 \mathrm{t} \mathrm{ha}^{-1} \mathrm{yr}^{-2}$. Accordingly, total area of locations in the study area with no changes in SCS between 2000 and 2010 was $31906.7 \mathrm{~km}^{2}$ (55.2\% of the total area). Total area of locations in the study area with increases in SCS was $22484.9 \mathrm{~km}^{2}$ (38.9\%), and total area of locations in the study area with decreases in SCS was $3460.4 \mathrm{~km}^{2}(5.9 \%)$.

The northeastern section of the reservoir region was where results show mainly increasing SCS. This section includes counties stretching from Yunyang to Zigui (including Fengjie, Wuxi, Wushan, Xingshan, and Badong counties). Moreover, this section accounted for $83.4 \%$ of total area where results show increases in SCS. The primary land cover type in this section in descending order was forest (44.0\%), shrubs and grassland (32.5\%), and cropland (20.4\%).

Results show that the distribution of locations with decreasing SCS was in the southwestern section of the study area, which was primarily densely populated flat terrain. This region stretches from Fengdu County to Jiangjin District along the Yangtze River.

\subsection{Temporal dynamics of SCS}

From 2000 to 2005, results show a small increase in the total amount of soil, but by only $5.3 \times 10^{8} \mathrm{t}$ (3.6\%) (Fig. 3). With the

Table 3

The erosion control practice factor $(P)$ for the various land use and land cover types.

\begin{tabular}{llllllll}
\hline & Crop land & Forest & Shrubs & Grassland & Water & Urban land & Bare land \\
\hline Value & 0.4 & 1 & 1 & 1 & 0 & 0 & 0 \\
\hline
\end{tabular}

exception of 2006, where the lowest soil retainment was measured in this study, results show a steady increase in the total amount of soil since 2005 , with an overall increase of $31.8 \times 10^{8} \mathrm{t}(4.8 \%)$ from 2005 to 2010.2007 was the year with the largest soil retainment. The annual average potential and actual annual soil erosion was equal to $16.21 \times 10^{8}$ and $0.83 \times 10^{8} \mathrm{t}$, respectively. Thus, the annual

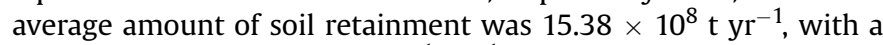
mean capacity of $2134.73 \mathrm{t} \mathrm{ha}^{-1} \mathrm{yr}^{-1}$.

SCS greatly depends on potential soil loss, which is predicable soil loss without vegetation cover. Rainfall was a major driving force for potential changes in soil loss, while slope and soil erodibility were considered constant in the short-term. Thus, annual changes in SCS mainly depended on annual changes in rainfall. Results show that the correlation between the amount of soil retainment and precipitation was highly significant $(r=-0.12, P<0.01)$. Precipitation in 2006 ( $572.9 \mathrm{~mm}$ ) was $47.4 \%$ lower than the annual averages from 2000 to 2010. Consequently, there was likely an underestimation in soil retention from 2006.

Potential rainfall-induced soil loss is closely related to topographic factors. For example, a plain in the southwestern section of the study area, despite having high annual rainfall, has a low potential soil loss due to the relatively flat terrain. In contrast, intense water erosion mainly occurred in the hilly and mountainous areas of the northeast. The production of most SCS was from sites with a slope greater than $8^{\circ}$ (Fig. 4), which accounted for $75.6 \%$ of total land area but greater than $90.2 \%$ of total SCS.

\subsection{Impact of factors that influenced SCS changes}

Main driving factors responsible for changes in SCS and SE of RDA in this study were precipitation, temperature, NDVI, GDP1, UPD, road density, cultivated area, conservation projects, and slope (Fig. 5). Results show that precipitation and temperature (i.e., climate) together explained $13 \%$ of variation in SCS and SE in the RDA model. Slope (i.e., topography) explained 63\% of variation in the RDA model. The remaining variables (anthropogenic: NDVI, GDP1, UPD, road density, cultivated area, and conservation projects) explained $13 \%$ of variation. The unexplained residual $10 \%$ variation may have resulted from integrated effects of other factors, including soil type, changes in land cover between years, and dynamic changes in landscape structure. Fig. 6 shows that soil erosion simulated using the USLE model was significantly linearly correlated to measured values $\left(R^{2}=0.812\right)$.

\section{Discussion}

\subsection{Accuracy of vegetation cover values}

Based on the relationship between the simulation values (USLE) and the measured values, model results on overall SCS services seems reasonable (Fig. 6).

Based on vegetation cover data and land use and land cover type maps, this study established one $C$ value for vegetation cover in each pixel. This is an improvement over determining the $C$ value based only on land use and land cover types since it also accounts for vegetation cover, which has a strong effect on soil erosion. Temporal analysis in this study shows that vegetation cover of the different land use and land cover types was not uniform or static but varied both spatially and over time. There was obvious spatial heterogeneity in vegetation cover for the forest type. For example, vegetation cover in mountain forests was greater than forests in areas of flat terrain. In mountainous areas, forest area had a high canopy density and there was abundant litter and understory vegetation that intercepted rainfall and protected the soil surface, thereby reducing the erosive forces of rainfall. In addition, the well- 

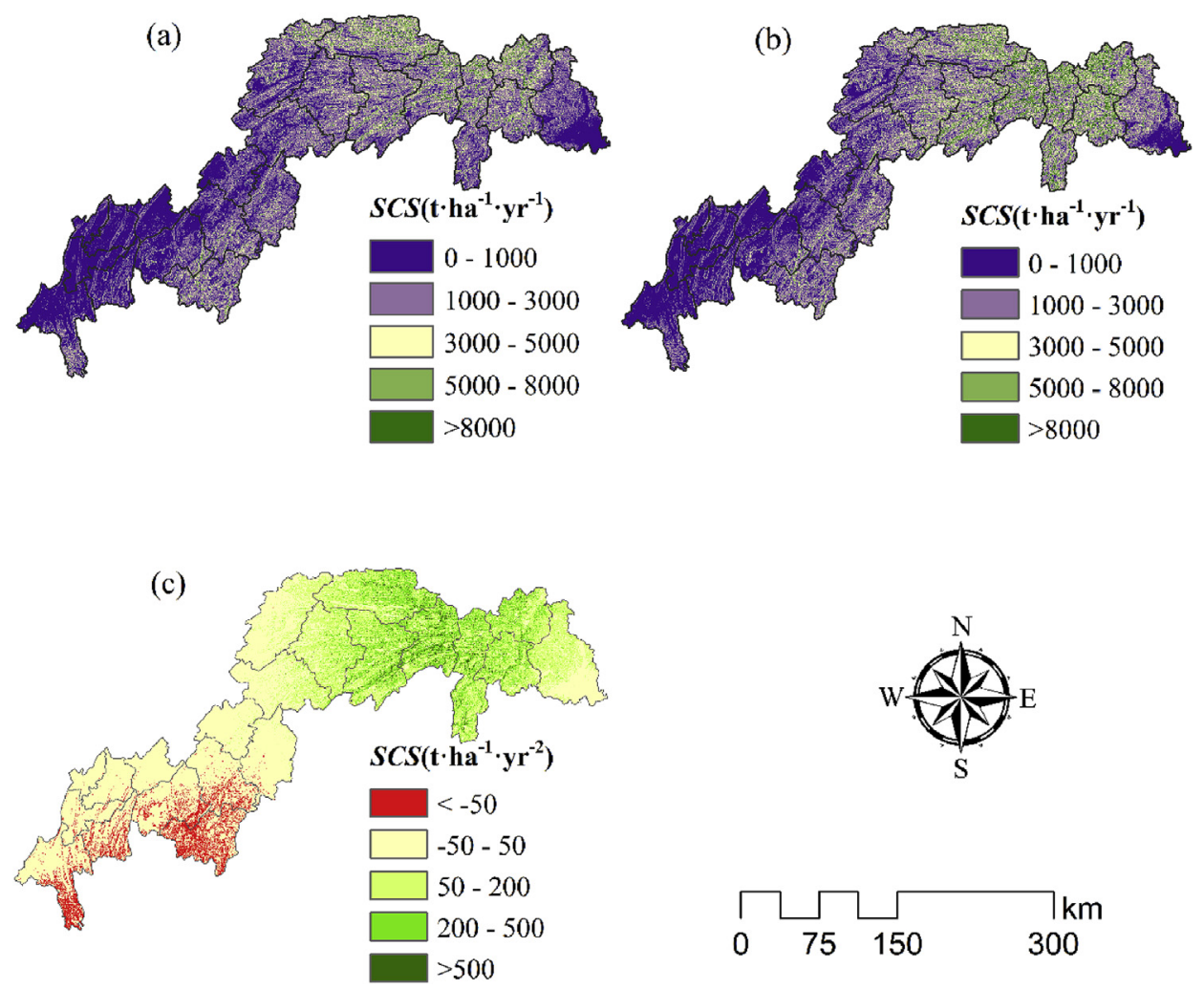

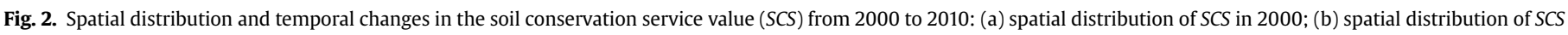
in 2010; (c) temporal changes in SCS from 2000 to 2010.

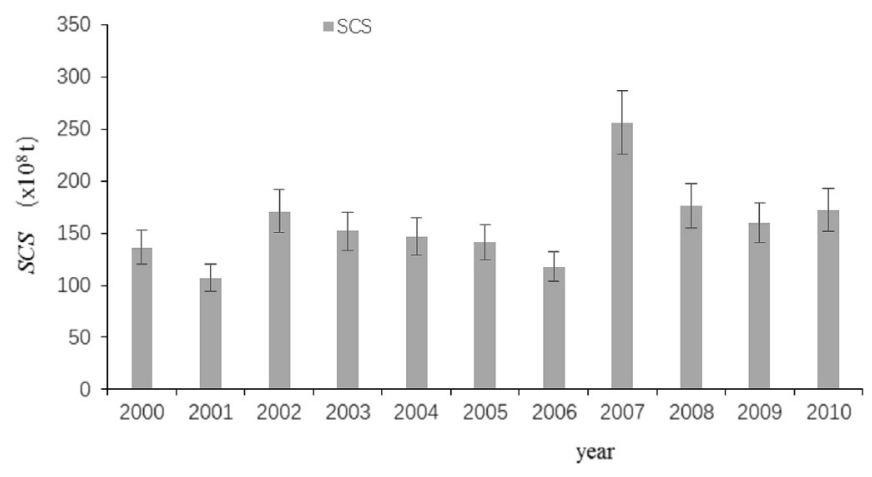

Fig. 3. The total soil conservation service (SCS) in the study area from 2000 to 2010 .

developed root system of a forest also protects soil against erosion (Kong et al., 2015). Therefore, calculating $C$ based on both vegetation cover and land use or land cover types can provide more accurate estimates of soil erosion.

\subsection{Soil conservation conditions}

There was an improvement in conditions of soil conservation moving from west to east. Poorer soil conservation was primarily found in the Jiangjin District, Yuzhong District, and Banan District, where the surface is even and vegetation cover (particularly forests) is lower. Distribution of higher soil conservation was mainly in mountainous areas, such as Wanzhou, Fengjie, Wushan, and Zigui counties as well as the Yiling District, where thick forested area is found and where it was less affected by human activity compared to the more densely populated western part of the study area

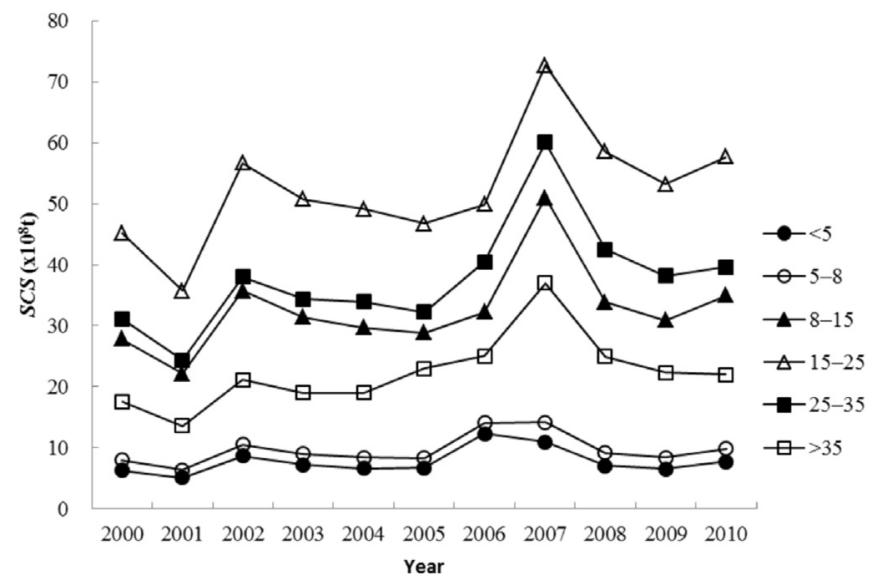

Fig. 4. Changes in the soil conservation service (SCS) as a function of slope in the study area from 2000 to 2010 .

(Wang et al., 2014b). This study stands in agreement with results from Li Yuechen on the importance of soil conservation in the Three Gorges Reservoir region (Li et al., 2011). Yan Enping found that areas in the Three Gorges Reservoir region with the highest ecosystem service values were mainly located in traditional forest zones, which was less affected by human activity. These included Zigui, Yichang, Wanzhou, and Fengjie counties. Those results were in agreement with conclusions from this study (Ketema and Yimer, 2014; Yan et al., 2015).

The soil conservation capacity of an ecosystem is closely related to its vegetation structure and will be influenced by such factors as the regional climate, landforms, soil types, vegetation cover, and 


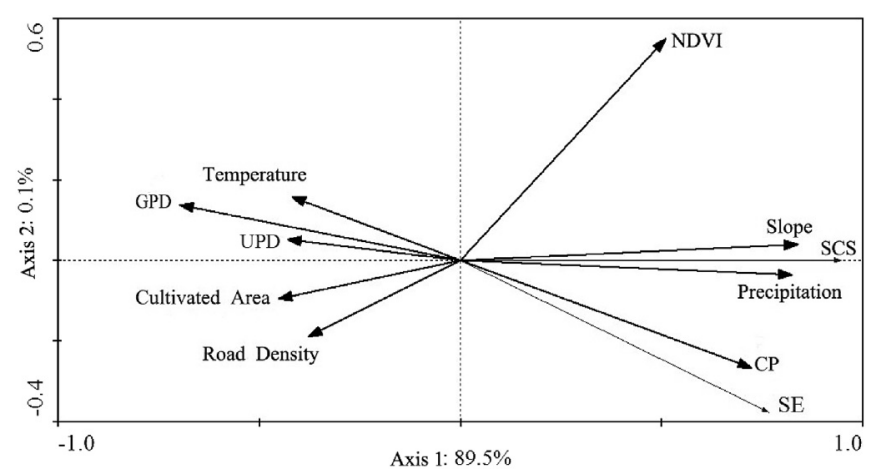

Fig. 5. Results of RDA ordination for the contributions of the environmental variables to the soil conservation service (SCS) and soil erosion (SE) changes during the study period. Parameter definitions: CP, conservation projects; GDP1, agricultural GDP; NDVI, the normalized difference vegetation index; UPD, urban population density.

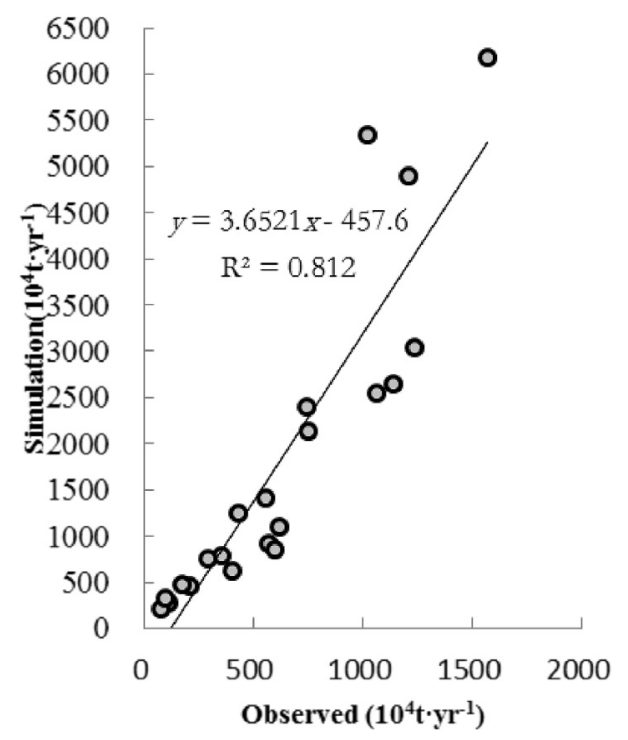

Fig. 6. The relationship between simulated (USLE) and observed mean annual soil erosion rates.

human impacts (Miao et al., 2010). A key reason for this was that Vshaped valleys in the upper reaches combined with abundant rainfall to create a high potential for soil erosion to occur, and the richer and more complex a forest ecosystem was in the lower reaches led to a higher soil conservation capacity. Both factors contributed to the high soil conservation capacity of the region (Zhu et al., 2013).

The strength of a soil conservation function of an ecosystem is closely related to the ecosystem type and vegetation cover. Typically, a forest (particularly a mixed forest) has the strongest capacity to conserve soil. It is followed by shrubs and grassland. Pastures and crops have the lowest capacity to conserve soil ( $\mathrm{Li}$ et al., 2009). Conservation also increases with increasing vegetation cover. In contrast, Cao et al. (2013) reported that grassland and shrubs offer better soil protection than forests, and that some forms of cultivated land provide better protection than shrubs (Cao et al., 2014). This confirms the conclusion that the soil conservation function depends on both vegetation type and vegetation cover and will therefore change as ecosystems age and environmental conditions change (Cao et al., 2013).

During the 10-year study period, soil conservation increased in the northeast and decreased in the southwest. High vegetation cover was associated to regions with the highest soil conservation values. Significant soil conservation was found in forest ecosystems, accounting for $54.6 \%$ of total soil conservation compared to 24.5 and $18.6 \%$ for shrub and grassland ecosystems, respectively. The forest ecosystem contributed most to soil conservation because it could, to some extent, intercept rainfall and reduce the potential energy of falling water. Additionally, much of the water reaches the surface through stemflow, further reducing its energy. Additional interception takes place by understory vegetation and the litter layer. The overall effect depends on rainfall characteristics (i.e., amount and intensity), tree characteristics (e.g., canopy density), and forest structure (e.g., vegetation cover).

An additional explanation of observed trends was related to increasing rainfall in the northeastern section of the study area throughout the study period. In southern China, due to the warm climate, vegetation cover improves where rainfall is abundant. The result was that both forest area and vegetation cover in forests increased, thereby improving the soil conservation capacity of forest ecosystems. In 2000, when an ecological engineering program was implemented, forest cover continuously increased, thereby improving the soil conservation function.

\subsection{Redundancy analysis}

RDA showed that among the driving forces, the contribution of topography (slope) was strongest (63\%). It was followed by climate (precipitation, 11\%). Human activity in the study area is determined by topography and other land characteristics. For example, land reclamation by harvesting forests for agriculture was most common on flat terrain and was therefore predominant in the western section of the study area. Such human activity will influence the soil conservation capacity of an ecosystem by changing its structure. For example, cultivation of farmland disrupts the soil surface by removing vegetation and litter and by disturbing surface soil through plowing, leaving the soil surface bare during the winter, which greatly increases the vulnerability of soil to erosion processes. Thus, farmland expansion will directly decrease the soil conservation capacity of an ecosystem. In addition, the rising water in the Three Gorges Reservoir has had a strong effect on the soil conservation capacity. From 2000 to 2007, the water surface of the reservoir rose to $175 \mathrm{~m}$, an increase of $45 \mathrm{~m}$ when compared to the pre-construction water levels. The rising water directly increased disturbances to ecosystems via human activity. It also resulted in landslides.

Miao also noted the importance of unsustainable human activity in the study area through the reduction of soil conservation ecosystem services (Miao et al., 2011). Human activity can easily cause fluctuation in the soil conservation environment, resulting in changes to spatial patterns of soil conservation and further endangering normal performance of ecosystem service functions in the Three Gorges Reservoir region.

\section{Conclusions}

Results show an increase in forest and vegetation cover area from southwest to northeast in the study area, thereby increasing the ecosystem service function of soil conservation. This increase is the result of a combination of higher population density in the southwest, greater cultivation of flat land, and increases in forest cover in the northeast, leading to greater overall soil protection.

To date only limited research is available on the relationship between soil conservation and the value of this ecosystem service, and this also includes spatial and temporal variations of these factors. By identifying spatial distribution of SCS and SE, this study provides empirical support for the future management of 
ecosystems in the study area in which to promote soil conservation. Specifically, land managers must find ways to decrease soil erosion in the heavily populated southwestern section of the study area by increasing green space or vegetation cover of existing green space while also applying techniques such as no-till cultivation or planting cover crops during the fallow season to protect agricultural soils. In the northeast, where soil conservation generally remains in good standing, land managers must protect forests responsible for high SCS and low SE. For example, the avoidance of forest clearcutting is recommended, particularly in steep terrain, and it is also recommended that any harvested forest area is reforested as soon as possible to protect against soil erosion.

The soil conservation capacity of ecosystems is of great importance to the maintenance of the ecological balance of the Three Gorges Reservoir region, and it contributes greatly to the enhancement of ecosystem management and protection. Moreover, it also helps to contain degradation in the soil conservation capacity while continually strengthening soil conservation in the Three Gorges Reservoir region.

\section{Acknowledgements}

This study was supported by National Foundation of Natural Sciences of China(No. 41171442, No. 70873121 and No. 41571482).We would like to thank Geoff Hart for his help in writing this paper as well as journal editors and anonymous reviewers for their comments on an earlier version of this manuscript.

\section{References}

Aiello, A., Adamo, M., Canora, F., 2015. Remote sensing and GIS to assess soil erosion with RUSLE3D and USPED at river basin scale in southern Italy. Catena 131, $174-185$.

Al-Wadaey, A., Ziadat, F., 2014. A participatory GIS approach to identify critical land degradation areas and prioritize soil conservation for mountainous olive groves (case study). J. Mt. Sci. 11, 782-791.

Austin, N.J., Muller, J.P., Gong, L., Zhang, J., 2013. A regional investigation of urban land-use change for potential landslide hazard assessment in the Three Gorges Reservoir Area, People's Republic of China: Zigui to Wanzhou. Int. J. Remote Sens. 34, 2983-3011.

Borges, T.K.D., Montenegro, A.A.D., dos Santos, T.E.M., da Silva, D.D., Silva, V.D.P.E., 2014. Effect of conservation practices on soil moisture and maize (Zea mays L.) cropping in the semi-arid northeast of Brazil. Rev. Bras. Cienc. Solo 38 1862-1873.

Bratman, G.N., Daily, G.C., Levy, B.J., Gross, J.J., 2015. The benefits of nature experience: improved affect and cognition. Landsc. Urban Plan. 138, 41-50.

Cao, S.X., 2015. Political ecology of nation-states with examples from Chinese history. Soc. Indic. Res. 124, 445-462.

Cao, S.X., Li, S.R., Ma, H., Sun, Y.T., 2015a. Escaping the resource curse in China. Ambio 44, 1-6.

Cao, S.X., Lv, Y., Zheng, H.R., Wang, X., 2015b. Research of the risk factors of China's unsustainable socioeconomic development: lessons for other nations. Soc Indic. Res. 123, 337-347.

Cao, S.X., Ma, H., Yuan, W.P., Wang, X., 2014. Interaction of ecological and social factors affects vegetation recovery in China. Biol. Conserv. 180, 270-277.

Cao, S.X., Zhang, J., 2015. Political risks arising from the impacts of large-scale afforestation on water resources of the Tibetan Plateau. Gondwana Res. 28, 898-903.

Cao, Y.G., Bai, Z.K., Zhou, W., Wang, J., 2013. Forces driving changes in cultivated land and management countermeasures in the Three Gorges Reservoir Area, China. J. Mt. Sci. 10, 149-162.

Costanza, R., dArge, R., deGroot, R., Farber, S., Grasso, M., Hannon, B., Limburg, K., Naeem, S., Oneill, R.V., Paruelo, J., Raskin, R.G., Sutton, P., vandenBelt, M., 1997. The value of the world's ecosystem services and natural capital. Nature 387, $253-260$.

Chai, B., Tong, J., Jiang, B., Yin, K.L., 2014. How does the water-rock interaction of marly rocks affect its mechanical properties in the Three Gorges reservoir area, China? Environ. Earth Sci. 72, 2797-2810.

Chen, N.S., Chen, M.L., Li, J., He, N., Deng, M.F., Tanoli, J.I., Cai, M., 2015. Effects of human activity on erosion, sedimentation and debris flow activity-a case study of the Qionghai Lake watershed, southeastern Tibetan Plateau, China. Holocene 25, 973-988.

Cohen, M.J., Shepherd, K.D., Walsh, M.G., 2005. Empirical reformulation of the Universal Soil Loss Equation for erosion risk assessment in a tropical watershed. Geoderma 124, 235-252.
Dick, M., da Silva, M.A., Dewes, H., 2015. Life cycle assessment of beef cattle production in two typical grassland systems of southern Brazil. J. Clean. Prod. 96, 426-434.

Faverial, J., Sierra, J., 2014. Home composting of household biodegradable wastes under the tropical conditions of Guadeloupe (French Antilles). J. Clean. Prod. 83, $238-244$.

Franzluebbers, A.J., 2010. Achieving soil organic carbon sequestration with conservation agricultural systems in the Southeastern United States. Soil Sci. Soc. Am. J. 74, 347-357.

Guo, Z.W., Xiao, X.M., Gan, Y.L., Zheng, Y.J., 2003. Landscape planning for a rural ecosystem: case study of a resettlement area for residents from land submerged by the Three Gorges Reservoir, China. Landsc. Ecol. 18, 503-512.

Irvem, A., Topaloglu, F., Uygur, V., 2007. Estimating spatial distribution of soil loss over Seyhan River Basin in Turkey. J. Hydrol. 336, 30-37.

Ketema, H., Yimer, F., 2014. Soil property variation under agroforestry based conservation tillage and maize based conventional tillage in Southern Ethiopia. Soil Tillage Res. 141, 25-31.

Kinzig, A.P., Ehrlich, P.R., Alston, L.J., Arrow, K., Barrett, S., Buchman, T.G., Daily, G.C., Levin, B., Levin, S., Oppenheimer, M., Ostrom, E., Saari, D., 2013. Social norms and global environmental challenges: the complex interaction of behaviors, values, and policy. Bioscience 63, 164-175.

Kong, D.X., Miao, C.Y., Borthwick, A.G.L., Duan, Q.Y., Liu, H., Sun, Q.H., Ye, A.Z., Di, Z.H., Gong, W., 2015. Evolution of the Yellow River Delta and its relationship with runoff and sediment load from 1983 to 2011. J. Hydrol. 520, 157-167.

Kyalo, D., Zhunusova, E., Holm-Muller, K., 2014. Estimating the joint effect of multiple soil conservation practices: a case study of smallholder farmers in the Lake Naivasha basin, Kenya. Land Use Pol. 39, 177-187.

Lee, S., 2004. Soil erosion assessment and its verification using the Universal Soil Loss Equation and geographic information system: a case study at Boun, Korea. Environ. Geol. 45, 457-465.

Li, F., Wang, R., Hu, D., Ye, Y., Yang, W., Liu, H., 2014a. Measurement methods and applications for beneficial and detrimental effects of ecological services. Ecol. Indic. 47, 102-111.

Li, F., Ye, Y., Song, B., Wang, R., 2015. Evaluation of urban suitable ecological land based on the minimum cumulative resistance model: a case study from Changzhou, China. Ecol. Model. 318, 194-203.

Li, F., Ye, Y.P., Song, B.W., Wang, R.S., Tao, Y., 2014b. Assessing the changes in land use and ecosystem services in Changzhou municipality, Peoples' Republic of China, 1991-2006. Ecol. Indic. 42, 95-103.

Li, Y.C., Liu, C.X., Yuan, X.Z., 2009. Spatiotemporal features of soil and water loss in three Gorges reservoir area of chongqing. J. Geogr. Sci. 19, 81-94.

Li, Y.C., Liu, C.X., Zhang, H., Gao, X., 2011. Evaluation on the human settlements environment suitability in the three Gorges reservoir area of chongqing based on RS and GIS. J. Geogr. Sci. 21, 346-358.

Liu, M.X., Du, W.Z., Zhang, H.L., 2014a. Changes of preferential flow path on different altitudinal zones in the Three Gorges Reservoir Area, China. Can. J. Soil Sci. 94, $177-188$.

Liu, Y.J., Wang, T.W., Cai, C.F., Li, Z.X., Cheng, D.B., 2014b. Effects of vegetation on runoff generation, sediment yield and soil shear strength on road-side slopes under a simulation rainfall test in the Three Gorges Reservoir Area, China. Sci Total Environ 485, 93-102.

Lopez-Garrido, R., Madejon, E., Murillo, J.M., Moreno, F., 2011. Short and long-term distribution with depth of soil organic carbon and nutrients under traditional and conservation tillage in a Mediterranean environment (southwest Spain). Soil Use Manag. 27, 177-185.

Luo, L.G., Wang, Y., Qin, L.H., 2014. Incentives for promoting agricultural clean production technologies in China. J. Clean. Prod. 74, 54-61.

Lou, Y.L., Xu, M.G., Chen, X.N., He, X.H., Zhao, K., 2012. Stratification of soil organic C $\mathrm{N}$ and $\mathrm{C}$ : $\mathrm{N}$ ratio as affected by conservation tillage in two maize fields of China. Catena 95, 124-130.

McDonough, S., Gallardo, W., Berg, H., Trai, N.V., Yen, N.Q., 2014. Wetland ecosystem service values and shrimp aquaculture relationships in Can Gio, Vietnam. Ecol. Indic. 46, 201-213.

Mendenhall, C.D., Karp, D.S., Meyer, C.F.J., Hadly, E.A., Daily, G.C., 2014b. Predicting biodiversity change and averting collapse in agricultural landscapes. Nature 509, 213-217.

Miao, C.Y., Ashouri, H., Hsu, K.L., Sorooshian, S., Duan, Q.Y., 2015. Evaluation of the PERSIANN-CDR daily rainfall estimates in capturing the behavior of extreme precipitation events over China. J. Hydrometeorol. 16, 1387-1396.

Miao, C.Y., Ni, J.R., Borthwick, A.G.L., 2010. Recent changes of water discharge and sediment load in the Yellow River basin, China. Prog. Phys. Geogr. 34, 541-561.

Miao, C.Y., Ni, J.R., Borthwick, A.G.L., Yang, L., 2011. A preliminary estimate of human and natural contributions to the changes in water discharge and sediment load in the Yellow River. Glob. Planet Change 76, 196-205.

Mwaniki, M.W., Agutu, N.O., Mbaka, J.G., Ngigi, T.G., Waithaka, E.H., 2015. Landslide scar/soil erodibility mapping using Landsat TM/ETM+ bands 7 and 3 Normalised Difference Index: a case study of central region of Kenya. Appl. Geogr. 64, $108-120$.

Ngetich, K.F., Diels, J., Shisanya, C.A., Mugwe, J.N., Mucheru-muna, M., Mugendi, D.N., 2014. Effects of selected soil and water conservation techniques on runoff, sediment yield and maize productivity under sub-humid and semiarid conditions in Kenya. Catena 121, 288-296.

Qu, J.J., Cao, S.X., Li, G.S., Niu, Q.H., Feng, Q., 2014. Conservation of natural and cultural heritage in Dunhuang, China. Gondwana Res. 26, 1216-1221.

Renison, D., Hensen, I., Suarez, R., Cingolani, A.M., Marcora, P., Giorgis, M.A., 2010. 
S180

Q. Xian et al. / Journal of Cleaner Production 163 (2017) S172-S180

Soil conservation in Polylepis mountain forests of central Argentina: is livestock reducing our natural capital? Austral Ecol. 35, 435-443.

Then, X.J., Lu, B.H., Zhou, D.W., 2016. Using GIMMS NDVI time series to estimate the impacts of grassland vegetation cover on surface air temperatures in the temperate grassland region of China. Remote Sens. Lett. 7, 229-238.

Chen, Z.Y., Gong, Y.W., Li, Y.H., Lu, R.M., 2010. Analysis and modeling of soil conservation measures in the three Gorges reservoir area in China. Catena 81, 104-112.

Tao, Y., Li, F., Wang, R.S., Zhao, D., 2015. Effects of land use and cover change on terrestrial carbon stocks in urbanized areas: a study from Changzhou, China. J. Clean. Prod. 103, 651-657.

Tend, H.F., Russel, R.A.V., Shi, Z., Behrens, T., Chappell, A., Bui, E., 2016. Assimilating satellite imagery and visible-near infrared spectroscopy to model and map soil loss by water erosion in Australia. Environ. Model. Softy 77, 156-167.

Thierfelder, C., Wall, P.C., 2012. Effects of conservation agriculture on soil quality and productivity in contrasting agro-ecological environments of Zimbabwe. Soil Use Manas. 28, 209-220.

Vandandorj, S., Gantsetseg, B., Boldgiv, B., 2015. Spatial and temporal variability in vegetation cover of Mongolia and its implications. J. Arid. Land 7, 450-461.

Van den Pete, A., Govers, G., Diels, J., Gillijns, K., Demuzere, M., 2010. Assessing the effect of soil tillage on crop growth: a meta-regression analysis on European crop yields under conservation agriculture. Eur. J. Agron. 33, 231-241.

Wang, Q., Yuan, X.Z., Lu, H., 2014a. Influence of the Three Gorges Reservoir on the vegetation of its drawdown area: effects of water submersion and temperature on seed germination of Xanthium sibiricum (Compositae). Pol. J. Ecol. 62, 25-36.

Wang, Q., Yuan, X.Z., Willison, J.H.M., Zhang, Y.W., Lu, H., 2014b. Diversity and above-ground biomass patterns of vascular flora induced by flooding in the drawdown area of China's Three Gorges Reservoir. PLo One 9. http:// dx.doi.org/10.1371/journal.pone.0100889.

Wu, L., Lu, X., Ma, X.Y., 2016. Spatiotemporal distribution of rainfall erosivity in the Yanhe River watershed of hilly and gully region, Chinese Loess Plateau. Environ. Earth Sci. 75, 13.

Yon, E.P., Lin, H., Wang, G.X., Sun, H., 2015. Improvement of forest carbon estimation by integration of regression modeling and spectral unmixing of Landsat data.
IEEE Geosci. Remote Sens. Lett. 12, 2003-2007.

Man, T.M., Yang, L.Z., Campbell, C.D., 2003. Microbial biomass and metabolic quotent of soils under different land use in the Three Gorges Reservoir area. Geoderma 115, 129-138. http://dx.doi.org/10.1061/\%28ASCE\%29HE.19435584.0001037.

Yang, H.C., Wang, G.Q., Jiang, H., Fang, H.Y., Ishidaira, H., 2015. Integrated modeling approach to the response of soil erosion and sediment export to land-use change at the basin scale. J Hydro Eng 20. http://dx.doi.org/10.1061/\%28ASCE \%29HE.1943-5584.0001037.

Yang, Y., Wang, G.Q., Wang, L.J., Yu, J.S., Xu, Z.X., 2014. Evaluation of gridded precipitation data for driving SWAT model in area upstream of Three Gorges Reservoir. PLoS One 9. http://dx.doi.org/10.1371/journal.pone.0112725.

Chang, J.Z., Zhao, T.Y., Jiang, C.C., Coo, S.X., 2016. Opportunity cost of water allocation to afforestation rather than conservation of natural vegetation in China. Land Use Policy 50, 67-73.

Chang, M.Y., Wang, F.J., Chen, F., Malemela, M.P., Zhang, H.L., 2013. Comparison of three tillage systems in the wheat-maize system on carbon sequestration in the North China Plain. J. Clean. Prod. 54, 101-107.

Chang, Z.X., Wang, X., Zhao, X.L., Lu, B., Ye, L., Zuo, L.J., Wen, Q.K., Lieu, F., Xu, J.Y., Hu, S.G., 2014. A 2010 update of National Land Use/Cover Database of China at 1:100000 scale using medium spatial resolution satellite images. Remote Sens. Environ. 149, 142-154.

Zheng, H.R., Gao, S.X., 2015. Threats to China's biodiversity by contradictions policy. Ambo 44, 23-33.

Chou, Y., Gro, B., Wang, S.X., Tao, H.P., 2015. An estimation method of soil wind erosion in Inner Mongolia of China based on geographic information system and remote sensing. J. Arid. Land 7, 304-317.

Thu, A.X., Wang, P., Zhu, T.X., Chen, L.J., Cai, Q.G., Diu, H.P., 2013. Modeling runoff and soil erosion in the Three-Gorge Reservoir drainage area of China using limited plot data. J. Hydrol. 492, 163-175.

Zhu, B., Wang, Z.H., Wang, T., Dong, Z.X., 2012. Non-point-source nitrogen and phosphorus loadings from a small watershed in the Three Gorges Reservoir area. J. Mt. Sci. 9, 10-15. 